\title{
Application of response surface methodology in describing the performance of mixed ceramic tool when turning AISI 4140 steel
}

\author{
Mohamed Elbah $^{1, a}$, Hamdi Aouici ${ }^{1,2}$, Ikhas Meddour ${ }^{1,2}$, Mohamed Athmane Yallese $^{1}$ \\ AND LAKHDAR BOULANOUAR ${ }^{3}$ \\ 1 Mechanics and Structures Research Laboratory (LMS), May 8th 1945 University, P.O. Box 401, 24000 Guelma, Algeria \\ 2 ENST-ex CT siege DG. SNVI, Route Nationale No. 5 Z.I., 16012 Rouiba, Algerie \\ 3 LRTAPM, Université Badji-Moukhtar, B12, 23000 Annaba, Algérie
}

Received 29 May 2015, Accepted 23 September 2015

\begin{abstract}
Statistical tools, as well as mathematical ones, have been widely adopted and their performance has been shown in different engineering problems where randomicity usually exists. In the realm of engineering, merging statistical analysis into structural evaluation and assessment will be a tendency in the future. As a combination of mathematical and statistical techniques, response surface methodology has been successfully applied to design optimization, response prediction and model validation. The aim of this study was to evaluate the impact of factors such as cutting speed, feed rate, and depth of cut on cutting force components and surface roughness of a mixed ceramic (CC650) cutting tool during the hard turning process of AISI 4140 steel. The experimental results indicate that the proposed mathematical models suggested could adequately describe the performance indicators within the limits of the factors that are being investigated. The depth of cut is the most significant factor that influences the cutting force components and the surface roughness. However, there are other factors that provide secondary contributions to the performance indicators. In the case of surface roughness, the feed rate and the interaction of feed rate and depth of cut provide these contributions whilst for forces components, the feed rate, the interaction of feed rate and depth of cut and the cutting speed provide them.
\end{abstract}

Key words: Ceramic / hard turning / AISI 4140 / surface roughness / cutting force / RSM

\section{Introduction}

The machining of hardened steel components (45$70 \mathrm{HRC}$ ) has been extensively used to replace the grinding operations due to improvements in the performance of hard tool materials such as ceramics and cubic boron nitride. The possibility of eliminating coolant reduced processing costs and power consumption, improved material properties and productivity, flexibility in producing complex geometric errors, ability to machine thin wall sections, and comparable surface finish are the major benefits of hard turning $[1,2]$. Hence, hard turning is broadly used in many applications such as tools, dies, gears, cams, shafts, axles, and bearings [3,4]. The surface finish is an important parameter in the machining process. In machining of parts, surface quality is one of the most specified customer requirements. Major indication of surface quality on machined parts is surface roughness. It has formed an important design feature in many situations

\section{Nomenclature}

\begin{tabular}{|ll|}
\hline$a p$ & Depth of cut, mm \\
$f$ & Feed rate, mm.rev \\
$F a$ & Axial force, $\mathrm{N}$ \\
$F t$ & Tangential force, $\mathrm{N}$ \\
$F r$ & Thrust force, $\mathrm{N}$ \\
$\mathrm{HRC}$ & Rockwell hardness \\
$\mathrm{PRESS}$ & Predicted residual error sum of squares \\
$R^{2}$ & Determination coefficient \\
$R_{\mathrm{pred}}^{2}$ & Predicted coefficient \\
$R_{\mathrm{adj}}^{2}$ & Adjusted coefficient \\
$R a$ & Surface roughness, $\mu \mathrm{m}$ \\
$S S_{\mathrm{E}}$ & Error sum of squares \\
$S S_{\mathrm{R}}$ & Regression model to the sum of squares \\
$S S_{\mathrm{T}}$ & Total sum of squares \\
$V c$ & Cutting speed, m.min \\
$\alpha$ & Clearance angle, degree \\
$\gamma$ & Rake angle, degree \\
$\lambda$ & Inclination angle, degree \\
$\chi$ & Major cutting edge angle, degree \\
\hline
\end{tabular}

a Corresponding author: elbah_med@yahoo.fr 
such as parts subjected to fatigue loads, precision fits, fastener holes, and aesthetic requirements. In addition to tolerance, surface roughness imposes one of the most critical constraints for the selection of machines and cutting parameters in the process planning [1]. So, surface roughness is an important measure of the technological quality of a product and a factor that greatly influences manufacturing cost $[5,6]$.

The response surface methodology (RSM) is a family of statistical techniques for the design, empirical modeling and optimization of processes, where the responses of interest are influenced by several process variables (termed factors) $[7,8]$. RSM comprises the following three major components: (i) experimental design to determine the process factor' values based on which the experiments are conducted and data are collected; (ii) empirical modeling to approximate the relationship (i.e. the response surface) between responses and factors; (iii) optimization to find the best response value based on the empirical model. In addition, the above three stage procedure is typically operated in an iterative manner, where the information attained from previous iterations is utilized to guide the search for better response variables.

Related to the problem concerning our work, several works have been previously done using the RMS method as a tool for design of experiments in various area including metal cutting: milling process [9], grinding process [10], turning process [11], drilling processes [12], but also other processes like vibration process [13].

Hessainia et al. [14] used design of experiments for studying and minimizing the surface roughness $(R a)$ during machining of $42 \mathrm{CrMo} 4$. The process factors chosen were cutting speed, feed rate, depth of cut and tool vibration. These factors were optimized using response table and response graph, normal probability plot, interaction graphs and analysis of variance (ANOVA). In their discussion of results, the authors concluded that the feed rate has greater influence followed by cutting speed on surface roughness $(R a)$. The product of feed rate $(f \times f)$ has more influence compared to other interaction of $R a$. Based on the analysis, an empirical equation was developed to determine the surface roughness that was valid for the chosen factors only. The surface finish of the hard turning of AISI 52100 was studied using Taguchi's design method by Azizi et al. [15]. The machining characteristics were investigated based on surface roughness and cutting force. The machining parameters were optimized using ANOVA. Simple regression method was employed. An empirical model was developed to determine the percentage of improvement in surface roughness and cutting force. Kirby et al. [16] developed the prediction model for surface roughness in turning operation. The regression model was developed by a single cutting parameter and vibrations along three axes were chosen for in-process surface roughness prediction system. By using multiple regression and Analysis of Variance (ANOVA) a strong linear relationship among the parameters (feed rate and vibration measured in three axes) and the response (surface roughness) was found. The authors demonstrated that spindle speed and depth of cut might not necessarily have to be fixed for an effective surface roughness prediction model. Doniavi et al. [17] used response surface methodology (RSM) in order to develop empirical model for the prediction of surface roughness by deciding the optimum cutting condition in turning. The authors showed that the feed rate influenced surface roughness remarkably. With the increase in feed rate surface roughness was found to be increased. With increasing in cutting speed the surface roughness decreased. The analysis of variance was applied which showed that the influence of feed and speed were more in surface roughness than depth of cut. Davim and Figueira [18] performed statistical analysis to study the influence of cutting speed and feed rate on specific cutting pressure, and surface roughness in hard turning of AISI D2 cold work tool steel with conventional ceramic inserts. Feng and Wang [19] have developed a statistical regression technique for surface roughness in terms of process parameters that includes hardness, feed, point angle, depth of cut, and spindle speed in finish turning. Choudhury and El-Baradie [20] had used RSM and $2^{3}$ factorial designs for predicting surface roughness when turning high-strength steel. Thiele and Melkote [21] had used a three-factor complete factorial design to determine the effects of workpiece hardness and cutting tool edge geometry on surface roughness and machining forces.

In this paper, data of factorial design for the four responses (feed force, thrust force, tangential force and surface roughness) when turning AISI 4140 are used to predict the machinability models using RSM. The obtained machinability models are compared against each other using the relative error analysis, descriptive statistics and hypothesis testing. Three machining parameters were considered (cutting speed, feed rate and depth of cut). Therefore, this paper presents the following contributions.

\section{Experimental procedure}

\subsection{Material, workpiece and tool}

The material used in the experiment was AISI 4140 steel in the form of round bar $75 \mathrm{~mm}$ in diameter and $400 \mathrm{~mm}$ in length. The chemical composition and mechanical properties are listed in Table 1. The workpiece is hardened to $60 \mathrm{HRC}$. Its hardness was measured by a digital durometer DM2-D 390. It is of $72 \mathrm{~mm}$ in diameter and it is machined under dry conditions. The lathe used for machining operations is TOS TRENCIN; model SN40C, spindle power $6.6 \mathrm{~kW}$.

The cutting tool used was CC650, a mixed alumina $\left(\mathrm{Al}_{2} \mathrm{O}_{3} \sim 70 \%\right)$-based ceramic with titanium carbide (TiC $\sim 30 \%$ ). According to ISO standard, the tool is designated as CNGA120408 S01525, rhomboid (manufacturer: Sandvik). The insert was rigidly attached to a tool holder of ISO designation of PCBNR2525M12. The combination of the insert and the tool holder provided $80^{\circ}$ cutting edge angle, $-6^{\circ}$ rake angle and $-6^{\circ}$ clearance angle.

The three components of the cutting forces; feed force $(F a)$, thrust force $(F r)$ and tangential force $(F t)$, were 
Table 1. Chemical composition and mechanical properties of AISI 4140 steel.

\begin{tabular}{|c|c|c|c|c|c|c|}
\hline Composition & $\mathrm{Mn}$ & $\mathrm{Si}$ & $\mathrm{Cr}$ & $\mathrm{Cu}$ & $\overline{\mathrm{Al}}$ & $\mathrm{Ti}$ \\
\hline$(\mathrm{Wt} \%)$ & 0.43 & 0.24 & 1.10 & 0.02 & 0.025 & 0.004 \\
\hline Mechanical properties & Yield strength $\mathrm{MPa}$ & Tensi & ngth MPa & Elast & modulus GPa & Thermal conductivity W.mK ${ }^{-1}$ \\
\hline
\end{tabular}

recorded using a standard quartz dynamometer (Kistler 9257B) allowing measurements from -5 to $5 \mathrm{kN}$. Instantaneous roughness criteria measurements $(R a)$, for each cutting condition, are obtained by means of a Mitutoyo Surftest 201 roughness meter. The length examined is $2.4 \mathrm{~mm}$ with a basic span of 3 . The measured values of $R a$ are within the range 0.05 to $40 \mu \mathrm{m}$. Absolute roughness is directly measured on the same turned part, without disassembling, in order to reduce uncertainties due to resumption operations. The measurements are repeated 3 times at 3 reference lines equally positioned at $120^{\circ}$.

\subsection{Experiments design}

Response surface methodology (RSM) is a collection of mathematical and statistical techniques that are useful for the modeling and analysis of problems in which a response of interest is influenced by several variables and the objective is to optimize this response [5-7]. It is a sequential experimentation strategy for empirical model building and optimization.

By conducting experiments and applying regression analysis, a model of the response to some independent input variables can be obtained. Based on the model of the response, a near optimal point can then be deduced. RSM is often applied in the characterization and optimization of processes. In RSM, it is possible to represent independent process parameters in quantitative form as:

$$
Y=\varphi(V c, f, a p)
$$

where $\varphi$ is the response function. The approximation of $Y$ is proposed by using a non-linear (quadratic) mathematical model, which is suitable for studying the interaction effects of process parameters on machinability characteristics. In the present work, the RMS based second order mathematical model is given by:

$$
Y=a_{0}+\sum_{i=1}^{k} b_{i} X_{i}+\sum_{i, j}^{k} b_{i j} X_{i} X_{j}+\sum_{i=1}^{k} b_{i i} X_{i}^{2}
$$

where $b_{0}$ is the free term of the regression equation, the coefficients $b_{1}, b_{2}, \ldots b_{k}$ and $b_{11}, b_{22}, \ldots b_{k k}$ are the linear and the quadratic terms respectively; while $b_{12}, b_{13}, \ldots b_{k-1}$ are the interacting terms. $X i$ represents input parameters $(V c, f$, and $a p)$. The output surface roughness $(R a)$ and cutting force components $(F a, F r$ and $F t)$ are also called the response factors. The experimental plan is developed to assess the influence of cutting speed $(V c)$, feed rate $(f)$ and depth of cut $(a p)$ on three components force $(F a, F r$ and $F t$ ) and surface roughness $(R a)$.

The other factors such as type of abrasive, workpiece, dry, and cutting tool were constant. Three levels
Table 2. Assignment of the levels to the factors.

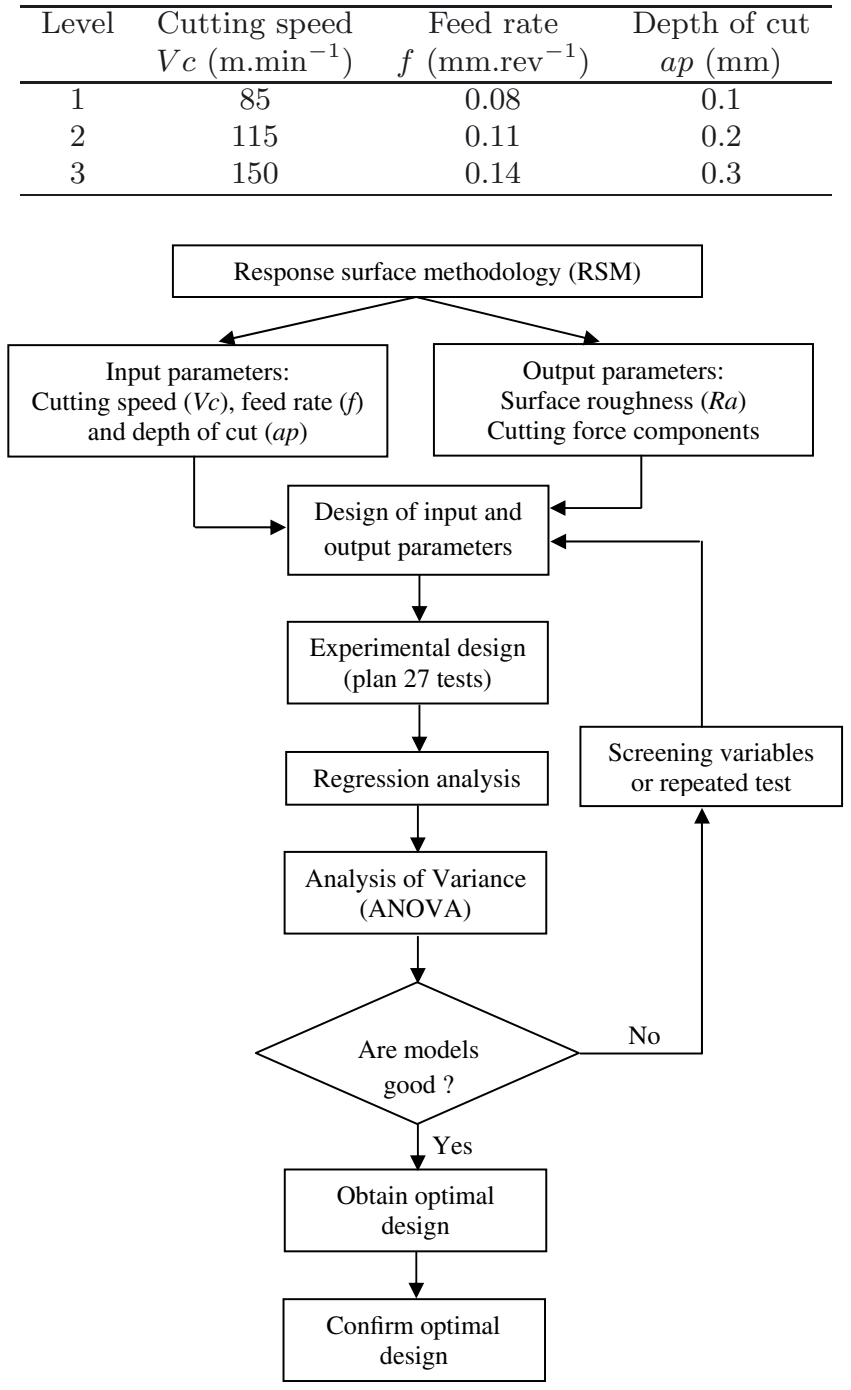

Fig. 1. Procedure of response surface methodology.

are defined for each cutting variable as given in Table 2 . The variable levels are chosen within the intervals recommended by cutting tool manufacturer. Three cutting variables at three levels led to a total of 27 tests.

The response surface method is a sequential process and its procedure can be summarized as shown in Figure 1.

Data were processed for Equation (1) using Design Expert 8.0.7 program including ANOVA to obtain the interaction between the process variables and the response. The quality of the fit of polynomial model was expressed by the coefficient of determination $R^{2}$, and its statical 
M. Elbah et al.: Mechanics \& Industry 17, 309 (2016)

Table 3. Experimental results for feed force, thrust force, tangential force and surface roughness.

\begin{tabular}{cccccccc}
\hline \multirow{2}{*}{ No. } & \multicolumn{3}{c}{ Machining parameters } & \multicolumn{4}{c}{ Response factors } \\
\cline { 2 - 7 } & $a p(\mathrm{~mm})$ & $f\left({\left.\mathrm{~mm} . \mathrm{rev}^{-1}\right)}^{-1}\left(\mathrm{~m} . \mathrm{min}^{-1}\right)\right.$ & $F a(\mathrm{~N})$ & $F r(\mathrm{~N})$ & $F t(\mathrm{~N})$ & $R a(\mu \mathrm{m})$ \\
\hline 1 & 0.1 & 0.08 & 80 & 13.85 & 38.62 & 43.61 & 0.33 \\
2 & 0.1 & 0.08 & 115 & 12.72 & 49.11 & 44.55 & 0.37 \\
3 & 0.1 & 0.08 & 150 & 13.48 & 58.36 & 46.75 & 0.39 \\
4 & 0.1 & 0.11 & 80 & 12.07 & 56.38 & 49.97 & 1.01 \\
5 & 0.1 & 0.11 & 115 & 18.51 & 77.49 & 45.00 & 1.12 \\
6 & 0.1 & 0.11 & 150 & 18.33 & 69.43 & 58.09 & 1.15 \\
7 & 0.1 & 0.14 & 80 & 18.38 & 65.58 & 65.02 & 1.36 \\
8 & 0.1 & 0.14 & 115 & 16.74 & 77.56 & 56.70 & 1.36 \\
9 & 0.1 & 0.14 & 150 & 25.49 & 97.23 & 67.92 & 1.50 \\
10 & 0.2 & 0.08 & 80 & 33.13 & 86.45 & 70.05 & 0.73 \\
11 & 0.2 & 0.08 & 115 & 33.37 & 101.37 & 81.49 & 0.70 \\
12 & 0.2 & 0.08 & 150 & 47.65 & 117.38 & 84.35 & 0.64 \\
13 & 0.2 & 0.11 & 80 & 43.95 & 100.85 & 107.99 & 0.76 \\
14 & 0.2 & 0.11 & 115 & 44.90 & 134.83 & 97.18 & 0.49 \\
15 & 0.2 & 0.11 & 150 & 49.77 & 143.31 & 108.48 & 0.61 \\
16 & 0.2 & 0.14 & 80 & 42.05 & 120.59 & 122.94 & 0.75 \\
17 & 0.2 & 0.14 & 115 & 61.83 & 151.87 & 129.00 & 0.76 \\
18 & 0.2 & 0.14 & 150 & 65.36 & 182.02 & 119.41 & 0.64 \\
19 & 0.3 & 0.08 & 80 & 63.84 & 137.3 & 114.48 & 0.44 \\
20 & 0.3 & 0.08 & 115 & 74.20 & 177.77 & 117.60 & 0.40 \\
21 & 0.3 & 0.08 & 150 & 75.46 & 193.10 & 116.86 & 0.38 \\
22 & 0.3 & 0.11 & 80 & 75.55 & 175.53 & 152.68 & 0.56 \\
23 & 0.3 & 0.11 & 115 & 86.64 & 202.27 & 146.04 & 0.53 \\
24 & 0.3 & 0.11 & 150 & 85.22 & 203.28 & 151.86 & 0.51 \\
25 & 0.3 & 0.14 & 80 & 77.96 & 192.26 & 191.43 & 0.55 \\
26 & 0.3 & 0.14 & 115 & 92.80 & 220.53 & 182.51 & 0.56 \\
27 & 0.3 & 0.14 & 150 & 108.79 & 245.97 & 167.57 & 0.64 \\
\hline
\end{tabular}

significance was checked by the $F$-test in the same program. The optimum values of the selected variables were obtained by solving the regression equation and by analyzing the response surface contour plots [22].

To prove the usability of a primary model, its adequacy is checked mainly by three criteria. The first $R^{2}$ criterion measures the amount of variation around the mean explained by the model [15]:

$$
\begin{aligned}
& R^{2}=\frac{S S_{\mathrm{R}}}{S S_{\mathrm{T}}}=1-\frac{S S_{\mathrm{E}}}{S S_{\mathrm{T}}} \\
& \left(0 \leq R^{2} \leq 1\right)
\end{aligned}
$$

with $S S_{\mathrm{T}}=S S_{\mathrm{E}}+S S_{\mathrm{R}}$ the total sum of squares, where, $S S_{\mathrm{E}}$ is the error sum of squares and the $S S_{\mathrm{R}}$ is regression model to the sum of squares. A value of $R^{2}$ close to1.0 is always preferred but does not imply an adequate model at all times because $R^{2}$ always increases with additional parameters, even non-significant ones. Therefore, an adjusted $R^{2}$ criterion can be used as a supplementary evaluation since it often decreases with the augmentation of non-significant parameters:

$$
\begin{aligned}
& R_{\mathrm{adj}}^{2}=1-\frac{S S_{\mathrm{E}} /(n-p)}{S S_{\mathrm{T}} /(n-1)}=1-\frac{n-1}{n-p}\left(1-R^{2}\right) \\
& \quad\left(0 \leq R_{\mathrm{adj}}^{2} \leq 1\right)
\end{aligned}
$$

where $p=k+1$. An $\mathrm{RS}$ model is well fitted with the samples if both $R^{2}$ and $R_{\text {adj }}^{2}$ are close to 1.0 with slight difference. However, a well-fitted model does not always accurately predict the responses of the unseen values of input parameters. Hence a third criterion $R_{\text {pred }}^{2}$ measuring the amount of variation in new data is also considered:

$$
\begin{gathered}
R_{\text {pred }}^{2}=1-\frac{P R E S S}{S S_{\mathrm{T}}} \\
\left(0 \leq R_{\text {pred }}^{2} \leq 1\right)
\end{gathered}
$$

where PRESS denotes the predicted residual error sum of squares and measures how the model fits the samples. In practice, $R_{\text {pred }}^{2}$ should also be close to 1.0 and a difference within 0.2 between $R_{\text {adj }}^{2}$ and $R_{\text {pred }}^{2}$ is acceptable for an RS model. Besides above three criterion indices, some plots such as the normal probability of internally studentized residuals versus predicted values or runs should also be checked $[23,24]$.

\section{Results and discussion}

Table 3 shows all the values of the response factors, surface roughness and cutting force components. The surface roughness $(R a)$ was obtained in the range of $\left(0.3^{-}\right.$ $1.50) \mu \mathrm{m}$, feed force $(F a)$, thrust force $(F r)$ and tangential force $(F t)$ were obtained in range of $(12.7-108.79) \mathrm{N}$, (38.6-245.97) N and (43.61-191.43) N, respectively. 
M. Elbah et al.: Mechanics \& Industry 17, 309 (2016)

Table 4. ANOVA result for feed force $(F a)$.

\begin{tabular}{|c|c|c|c|c|c|c|c|}
\hline Source & Sum of squares & $\overline{\mathrm{DF}}$ & Mean square & $F$-value & Prob. & Cont. \% & Remarks \\
\hline Model & 21676.1124 & 9 & 2408.45693 & 142.149377 & $<0.0001$ & & Significant \\
\hline$V c$ & 752.900185 & 1 & 752.900185 & 44.4368719 & $<0.0001$ & 3.455 & Significant \\
\hline$f$ & 1103.87342 & 1 & 1103.87342 & 65.1516401 & $<0.0001$ & 5.065 & Significant \\
\hline$a p$ & 19397.5065 & 1 & 19397.5065 & 1144.85894 & $<0.0001$ & 89.010 & Significant \\
\hline$V c \times f$ & 140.472137 & 1 & 140.472137 & 8.29079667 & 0.0104 & 0.645 & Significant \\
\hline$V c \times a p$ & 127.5312 & 1 & 127.5312 & 7.5270105 & 0.0139 & 0.585 & Significant \\
\hline$f \times a p$ & 159.845556 & 1 & 159.845556 & 9.43423395 & 0.0069 & 0.733 & Significant \\
\hline$V c^{2}$ & 2.49615 & 1 & 2.49615 & 0.1473251 & 0.7059 & 0.011 & No significant \\
\hline$f^{2}$ & 70.017094 & 1 & 70.017094 & 4.13247427 & 0.0580 & 0.321 & No significant \\
\hline$a p^{2}$ & 37.95135 & 1 & 37.95135 & 2.23992411 & 0.1528 & 0.174 & No significant \\
\hline Error & 288.033396 & 17 & 16.943141 & & & & \\
\hline Total & 21964.1458 & 26 & & & & 100 & \\
\hline \multicolumn{5}{|c|}{$\mathrm{SD}=412$} & \multicolumn{3}{|c|}{$R^{2}=0.9869$} \\
\hline \multicolumn{5}{|c|}{ Mean $=4857$} & \multicolumn{3}{|c|}{$R^{2}$ Adjusted $=0.9799$} \\
\hline \multicolumn{5}{|c|}{ Coefficient of variation $=8.48$} & \multicolumn{3}{|c|}{$R^{2}$ Predicted $=0.9671$} \\
\hline \multicolumn{5}{|c|}{ Predicted residual error of sum of squares (PRESS) $=722.4$} & \multicolumn{3}{|c|}{ Adequate precision $=38.223$} \\
\hline
\end{tabular}

\subsection{Statistical analysis}

The results from the cutting force components $(\mathrm{Fa}, \mathrm{Fr}$ and $F t)$ and the surface roughness $(R a)$ experimented as per the experimental plan are tabulated in Table 3. For the checking of the goodness of fit of the quadratic model obtained in this study, the test for significance of the regression model, the test for significance on individual model coefficients need to be performed. The analysis of ANOVA is usually applied to summarize the above tests performed.

Tables 4-7 show these results of ANOVA, respectively, for $F a, F r, F t$ and $R a$. This analysis was out for a $5 \%$ significance level, i.e., for a $95 \%$ confidence level. The last column of tables shows the factor contribution (percentage; Cont. \%) on the total variation, indicating the degree of influence on the result.

Table 4 shows the ANOVA table for response surface quadratic model for feed force $(F$ a). The model $F$-value of 142.149 implies that the model is significant. There is only a $0.01 \%$ chance that a "model $F$-Value" could occur due to noise. The value of Prob. in Table 4 for the model is less than 0.0001 which indicates that the model is significant, which is desirable as it indicates that the terms in the model have a significant effect on the response. In the same manner, the main effects of cutting speed $(V c)$, feed rate $(f)$, depth of cut $(a p)$ and the product of cutting speed and feed rate $(V c \times f)$, cutting speed and depth of cut $(V c \times a p)$ and feed rate and depth of cut $(f \times a p)$ are significant model terms. The interactions $V c \times V c, f \times f$ and $a p \times a p$ do not present any significant contribution on the obtained feed force.

The other important coefficient $R^{2}$ in the resulting ANOVA table is defined as the ratio of the explained variation to the total variation and is a measure of the degree of fit. When $R^{2}$ approaches to unity, the better response model fits the actual data. The value of $R^{2}$ calculated in Table 4 for this model is over 0.95 and reasonably close to unity, which is acceptable. It denotes that about $95 \%$ of the variability in the data is explained by this model. It also confirms that this model provides an excellent explanation of the relationship between the independent factors and the response.

The resulting ANOVA table for the quadratic model for thrust force is shown in Table 5 . The model $F$-value of 204.78 implies that the model is significant. Results from Table 5 indicate that the model is still significant. However the main effect of cutting speed $(V c)$, feed rate $(f)$ and depth of cut $(a p)$ and the two level interactions of cutting speed and feed rate $(V c \times f)$, cutting speed and depth of cut $(V c \times a p)$ and feed rate and depth of cut $(f \times$ ap) are the significant model terms. The $R^{2}$ value is high, close to 1 , which is desirable. The Pred. $R$-Squared of 0.9771 is in reasonable agreement with the Adj $R$-Squared of 0.9860 . The adjusted $R^{2}$ value is particularly useful when comparing models with different number of terms. Adequate Precision measures the signal to noise ratio. A ratio greater than 4 is desirable. Our ratio of 49.861 indicates an adequate signal. So, this model can be used to navigate the design space.

From the analysis of influence on the feed force $(F t)$ is summed up in Table 6. It can be indicated that the model is still significant. However the main effect of feed rate $(15.269 \%)$, depth of cut $(80.233 \%)$ and the two level interactions of feed rate and depth of cut $(2.552 \%)$ and the product $(1.331 \%)$ have statistical significances on $F \mathrm{t}$, in particular the depth of cut factor. The cutting speed and the interactions $V c \times f, V c \times a p, V c \times V c$ and $a p \times a p$ do not present any statistical significance on the tangential force $(F t)$.

The $R^{2}$ value is high, close to 1 , which is desirable. The Pred. $R$-Squared of 0.9636 is in reasonable agreement with the Adj $R$-Squared of 0.9796 . The adjusted $R^{2}$ value is particularly useful when comparing models with different number of terms. Adequate Precision measures the signal to noise ratio. A ratio greater than 4 is desirable. Our ratio of 39.932 indicates an adequate signal. So, this model can be used to navigate the design space. 
M. Elbah et al.: Mechanics \& Industry 17, 309 (2016)

Table 5. ANOVA result for thrust force $(F r)$.

\begin{tabular}{|c|c|c|c|c|c|c|c|}
\hline Source & Sum of squares & $\overline{\mathrm{DF}}$ & Mean square & $F$-value & Prob. & Cont. \% & Remarks \\
\hline Model & 90669.8938 & 9 & 10074.4326 & 204.779112 & $<0.0001$ & & Significant \\
\hline$V c$ & 6522.10764 & 1 & 6522.10764 & 132.57237 & $<0.0001$ & 7.196 & Significant \\
\hline$f$ & 8630.79014 & 1 & 8630.79014 & 175.434746 & $<0.0001$ & 9.523 & Significant \\
\hline$a p$ & 73509.3373 & 1 & 73509.3373 & 1494.19598 & $<0.0001$ & 81.104 & Significant \\
\hline$V c \times f$ & 230.806401 & 1 & 230.806401 & 4.6915128 & 0.0448 & 0.255 & Significant \\
\hline$V c \times a p$ & 441.896033 & 1 & 441.896033 & 8.98225044 & 0.0081 & 0.488 & Significant \\
\hline$f \times a p$ & 281.20101 & 1 & 281.20101 & 5.71586462 & 0.0287 & 0.310 & Significant \\
\hline$V c^{2}$ & 192.515585 & 1 & 192.515585 & 3.91319014 & 0.0643 & 0.212 & No significant \\
\hline$f^{2}$ & 759.204359 & 1 & 759.204359 & 15.4320546 & 0.0011 & 0.838 & Significant \\
\hline$a p^{2}$ & 67.6256463 & 1 & 67.6256463 & 1.37460046 & 0.2572 & 0.075 & No significant \\
\hline Error & 836.341918 & 17 & 49.1965834 & & & & \\
\hline Total & 91506.2358 & 26 & & & & 100 & \\
\hline \multicolumn{5}{|c|}{$\mathrm{SD}=7.01$} & \multicolumn{3}{|c|}{$R^{2}=0.9909$} \\
\hline \multicolumn{5}{|c|}{ Mean $=128.76$} & \multicolumn{3}{|c|}{$R^{2}$ Adjusted $=0.9860$} \\
\hline \multicolumn{5}{|c|}{ Coefficient of variation $=5.45$} & \multicolumn{3}{|c|}{$R^{2}$ Predicted $=0.9771$} \\
\hline \multicolumn{5}{|c|}{ Predicted residual error of sum of squares (PRESS) $=2094.81$} & \multicolumn{3}{|c|}{ Adequate precision $=49.861$} \\
\hline
\end{tabular}

Table 6. ANOVA result for tangential force $(F t)$.

\begin{tabular}{|c|c|c|c|c|c|c|c|}
\hline Source & Sum of squares & $\overline{D F}$ & Mean square & $F$-value & Prob. & Cont. $\%$ & Remarks \\
\hline Model & 51243.4661 & 9 & 5693.71845 & 139.446333 & $<0.0001$ & & Significant \\
\hline$V c$ & 3.32549067 & 1 & 3.32549067 & 0.08144545 & 0.7788 & 0.006 & No significant \\
\hline$f$ & 8139.17876 & 1 & 8139.17876 & 199.338734 & $<0.0001$ & 15.269 & Significant \\
\hline$a p$ & 42767.8569 & 1 & 42767.8569 & 1047.43866 & $<0.0001$ & 80.233 & Significant \\
\hline$V c \times f$ & 174.912248 & 1 & 174.912248 & 4.28382115 & 0.0540 & 0.328 & No significant \\
\hline$V c \times a p$ & 110.777633 & 1 & 110.777633 & 2.7130837 & 0.1179 & 0.208 & No significant \\
\hline$f \times a p$ & 1360.3513 & 1 & 1360.3513 & 33.316716 & $<0.0001$ & 2.552 & Significant \\
\hline$V c^{2}$ & 286307852 & 1 & 28.6307852 & 0.70120397 & 0.4140 & 0.054 & No significant \\
\hline$f^{2}$ & 709.433135 & 1 & 709.433135 & 17.3749106 & 0.0006 & 1.331 & Significant \\
\hline$a p^{2}$ & 9.91591852 & 1 & 9.91591852 & 0.24285333 & 0.6285 & 0.019 & No significant \\
\hline Error & 694.1252 & 17 & 40.8308941 & & & & \\
\hline Total & 51937.5913 & 26 & & & \multicolumn{3}{|c|}{100} \\
\hline \multicolumn{5}{|c|}{$\mathrm{SD}=6.39$} & \multicolumn{3}{|c|}{$R^{2}=0.9866$} \\
\hline \multicolumn{5}{|c|}{ Mean $=101.46$} & \multicolumn{3}{|c|}{$R^{2}$ Adjusted $=0.9796$} \\
\hline \multicolumn{5}{|c|}{ Coefficient of variation $=6.30$} & \multicolumn{3}{|c|}{$R^{2}$ Predicted $=0.9636$} \\
\hline \multicolumn{5}{|c|}{ ual error of sum of squares (PRESS) $=18$} & $\overline{\text { Adeq }}$ & ate precisi & $\mathrm{n}=39.932$ \\
\hline
\end{tabular}

The same procedure is applied to deal with the other response, surface roughness $(R a)$, and the resulting ANOVA for the quadratic model is shown in Table 7. The value of Prob. in Table 7 for this model is also less than 0.05 (i.e. $\alpha=0.05$, or $95 \%$ confidence) and indicates that the model is considered to be statistically significant.

The model $F$-value of 6.860 implies that the model is significant. The value of Prob. in Table 7 for the model is 0.0004 which indicates that the model is significant, which is desirable as it indicates that the terms in the model have a significant effect on the response.

The significant model terms include the main effect of factor $f$ (feed rate), factor ap (depth of cut) and interaction effect of factor $f \times a p$ (feed rate and depth of cut). The other model terms cannot be regarded as significant effect due to their "Prob. $>F$ " values greater than 0.05 . These insignificant model terms can be removed.

According to the results in ANOVA, a sensitivity analysis for the design factors in the surface roughness is performed and shown in the last column (Tab. 7). From the results of percent contribution for each significant design factor, the front two significant design factors in the surface roughness are factor depth of cut (44.39\%) and factor feed rate $(30.729 \%)$, and the interaction effect of factor, feed rate and depth of cut $(17.962 \%)$.

\subsection{Regression equations}

The relationship between the factors and the performance measures were modeled by quadratic regression. The regression equations obtained were as follows.

The feed force model $(F a)$ is given by Equation (6) with a determination coefficient $\left(R^{2}\right)$ of $98.69 \%$.

$$
\begin{aligned}
F a= & -14.377-0.096 V c+202.346 f+44.994 a p \\
& +1.563 V c \times f+0.931 V c \times a p+584.423 f \times a p \\
& -0.0005 V c^{2}-1316.872 f^{2}+251.5 a p^{2}
\end{aligned}
$$


M. Elbah et al.: Mechanics \& Industry 17, 309 (2016)

Table 7. ANOVA result for surface roughness $(R a)$.

\begin{tabular}{cccccccc}
\hline Source & Sum of squares & DF & Mean square & $F$-value & Prob. & Cont. \% & Remarks \\
\hline Model & 2.18304893 & 9 & 0.24256099 & 6.86033192 & 0.0004 & & Significant \\
$V c$ & $3.141 \mathrm{E}-05$ & 1 & $3.141 \mathrm{E}-05$ & 0.00088837 & 0.9766 & 0.001 & No significant \\
$f$ & 0.77708889 & 1 & 0.77708889 & 21.9783389 & 0.0002 & 30.729 & Significant \\
$a p$ & 1.12257123 & 1 & 1.12257123 & 31.7495865 & $<0.0001$ & 44.390 & Significant \\
$V c \times f$ & 0.00424808 & 1 & 0.00424808 & 0.120148 & 0.7331 & 0.168 & No significant \\
$V c \times a p$ & 0.0108 & 1 & 0.0108 & 0.30545548 & 0.5877 & 0.427 & No significant \\
$f \times a p$ & 0.45422308 & 1 & 0.45422308 & 12.8467526 & 0.0023 & 17.962 & Significant \\
$V c^{2}$ & 0.00253519 & 1 & 0.00253519 & 0.07170243 & 0.7921 & 0.100 & No significant \\
$f^{2}$ & 0.13884615 & 1 & 0.13884615 & 3.92697396 & 0.0639 & 5.490 & No significant \\
$a p^{2}$ & 0.01851852 & 1 & 0.01851852 & 0.52375768 & 0.4791 & 0.732 & No significant \\
Error & 0.60106959 & 17 & 0.03535703 & & & 100 & \\
Total & 2.78411852 & 26 & & & & $R^{2}=0.7841$ \\
\hline \multicolumn{7}{c}{ SD $=0.19$} & Adjusted $=0.6698$ \\
\hline \multicolumn{7}{c}{ Mean $=0.71$} & $R^{2}$ Predicted $=0.4619$ \\
\hline Predicted residual error of sum of squares (PRESS) $=1.5$ & Adequate precision $=8.919$
\end{tabular}

The thrust force model $(F r)$ is given by Equation $(7)$ and the determination coefficient $\left(R^{2}\right)$ is $99.09 \%$.

$$
\begin{aligned}
F r= & -134.25+0.990 V c+1193.348 f+209.025 a p \\
& +2.006 V c \times f+1.733 V c \times a p+775.149 f \times a p \\
& -0.0046 V c^{2}-4336.316 f^{2}+335.722 a p^{2}
\end{aligned}
$$

The tangential force model $(F t)$ is given by the following Equation (8). Its coefficient of determination is $98.66 \%$.

$$
\begin{aligned}
F t= & -95.865-0.0045 V c+1387.99 f+409.292 a p \\
& -1.748 V c \times f-0.868 V c \times a p+1704.914 f \times a p \\
& +0.0017 V c^{2}-4191.769 f^{2}-128.555 a p^{2}
\end{aligned}
$$

The roughness $R a$ model is given below in Equation (9). Its coefficient of determination $\left(R^{2}\right)$ is $78.41 \%$.

$$
\begin{aligned}
R a= & -0.761-0.0033 V c+25.123 f+0.580 a p \\
& +0.008 V c \times f-0.0085 V c \times a p-31.143 f \times a p \\
& +1.678 \times 10^{-5} V c^{2}-58.642 f^{2}+5.555 a p^{2}
\end{aligned}
$$

Figures 2 and 3 show the cutting forces components $(F a, F r$ and $F t$ ) and surface roughness $(R a)$ values obtained by experimentation and the values predicted by the quadratic model for mixed ceramic. It is clear that the predicted values are very close to the experimental readings. The adequacy of the quadratic model is verified using the analysis of variance (ANOVA). At a level of confidence of $95 \%$, the model is checked for its adequacy. As shown in Table 6, the model is adequate owing to the fact that the $P$-values of lack-of-fit are not significant. This implies that the model could fit and it is adequate

\subsection{Effect of machining parameters on surface response factors}

The three-dimension surface plots were drawn to illustrate the main and interactive effects of the independent variables on the dependent one. These graphs (Figs. 4 to 7) were obtained by fixing one variable at middle level (Tab. 2) while varying the remaining two variables and predicting the response variables $(F a, F r, F t$ and $R a$ ).

Figure 4 presents the effect of the feed rate and cutting speed on the feed force. Clearly, the cutting speed has a similar influence to that of the feed rate on the feed force. An increase of cutting speed results in an increase in the feed force, but with less effect when feed rate approaches 0.16-0.20 rev. $\min ^{-1}$.

Results of the combined effects of depth of cut and cutting speed on the thrust force $(F r)$ are presented in Figure 5. For dry condition, Figure 5 shows clearly that the thrust force increases significantly with depth of cut and cutting speed and the highest value occurs at highest depth of cut and highest cutting speed. It can be also observed that the $\mathrm{Fr}$ behaves linearly with depth of cut and nonlinearly with cutting speed.The increased depth of cut increases thrust force. As the depth of cut is increased, the cutting edge length in contact with the workpiece increases. This means that the working zone is out of the tool-nose radius [25].

The influence of depth of cut and feed rate on the tangential force $(F t)$ is presented in Figure 6. Both surface and contour plots show clearly a substantial linear increase of the $F t$ with depth of cut and a slight nonlinear increase with the feed rate. This figure shows that as the feed rate and the depth of cut increase the tangential force increases because of the sheared chip cross section that is getting larger together with the volume of the deformed metal. Therefore, the workpiece material becomes more resistant to shearing and there should be much effort applied to remove the chip. This trend is similar as results were reported by Aouici [26] when turning AISI H11 steel (52 HRC) using CBN7020 tool.

Figure 7 shows the combined effect of cutting speed and feed rate on the surface roughness at constant depth of cut. It is evident from the figure that the effect of feed rate is more significant than that of the cutting speed at 


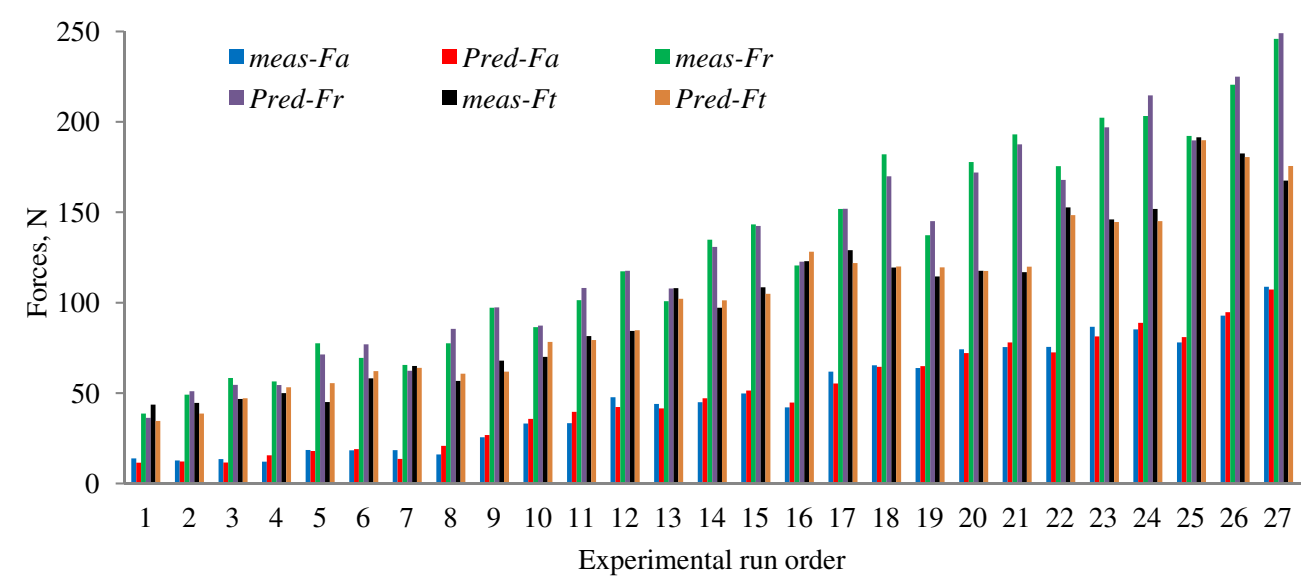

Fig. 2. Comparison between measured and predicted values for cutting force components.

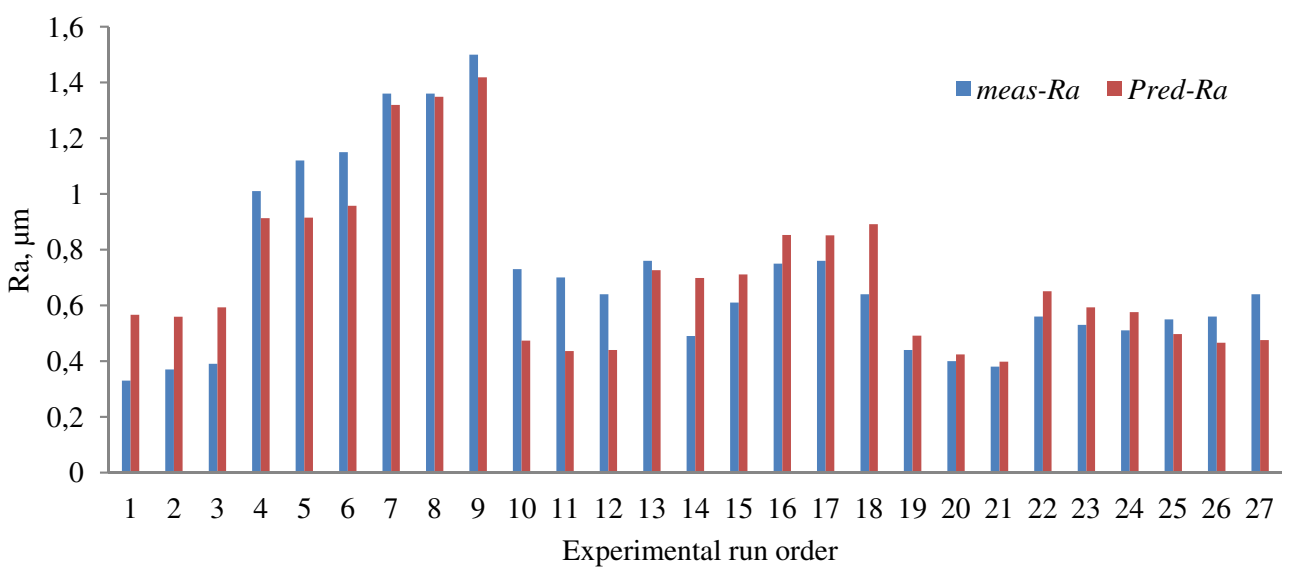

Fig. 3. Comparison between measured and predicted values for surface roughness.

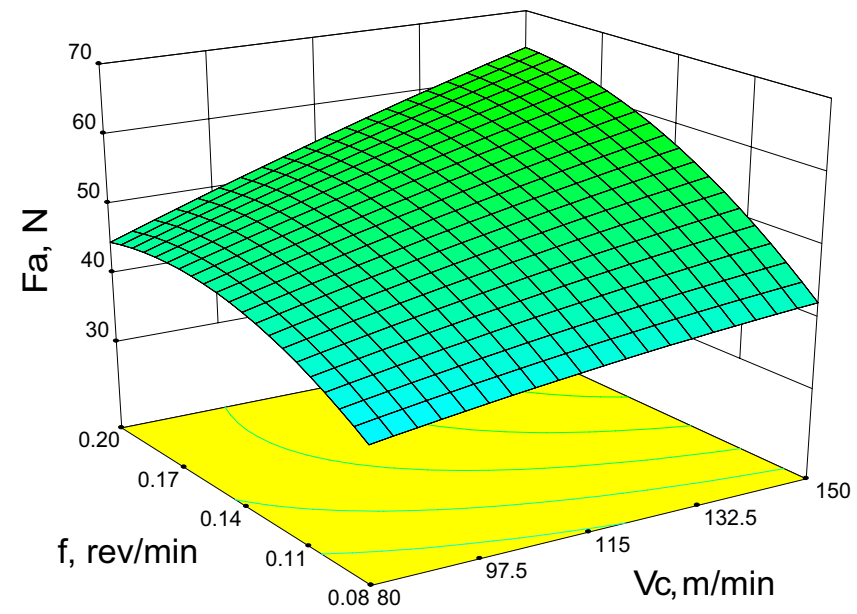

Fig. 4. The response surface of feed force according to change of feed rate and cutting speed.

constant depth of cut.This is because the increased feed rate increases cutting forces. As the feed rate is increased, the region of sheared chip increases, since resistance to material rupture is higher and hence requires larger efforts for chip removal [25]. From the contour plot we can easily

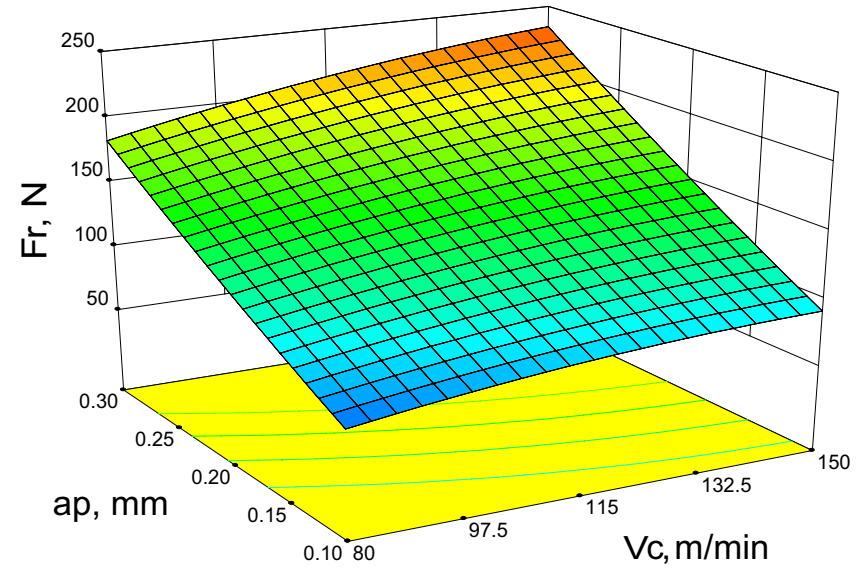

Fig. 5. The response surface of thrust force according to change of depth of cut and cutting speed.

predict the surface roughness and when both combined effect increases the surface roughness value increases substantially. 


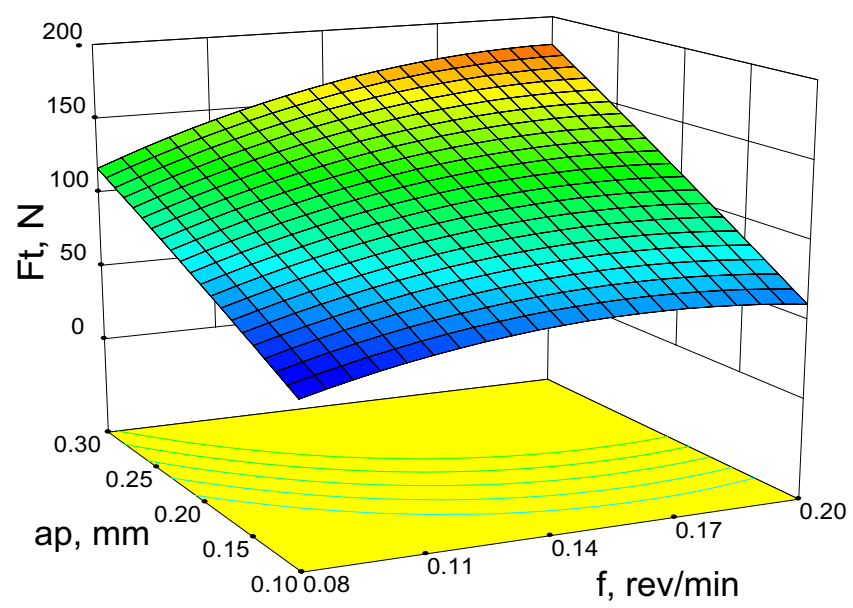

Fig. 6. The response surface of tangential force according to change of depth of and feed rate.

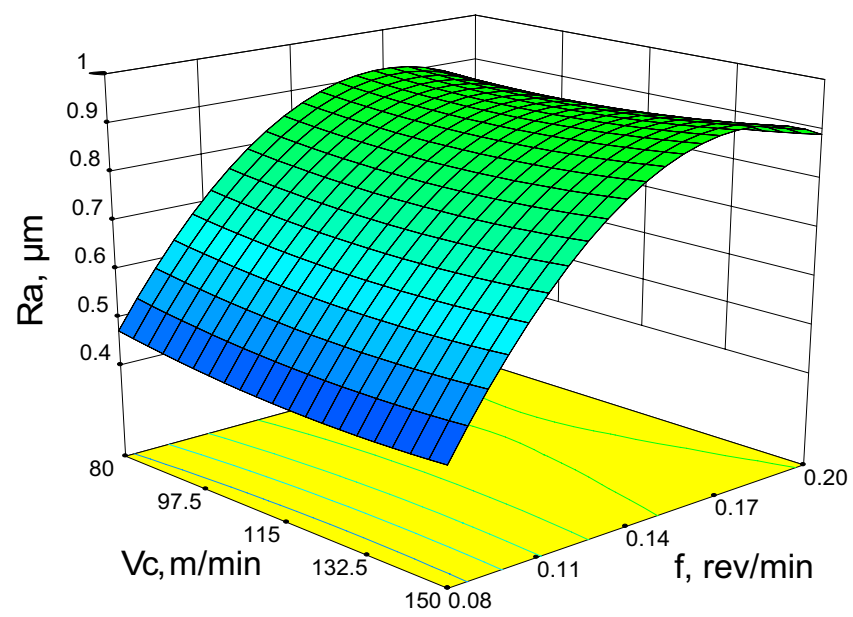

Fig. 7. The response surface of surface roughness according to change of cutting speed and feed rate.

\subsection{D surface topography}

The 3D surface profiles of the hard turned surfaces along the feed direction are shown in Figure 8. It must be noted that the both $3 \mathrm{D}$ profiles have represented pure roughness values, i.e. the turned surface topography in Figures $8 \mathrm{a}$ and $8 \mathrm{~b}$ shows well-defined peaks and valleys, this is mainly because when the turning operation process uses a single cutting edge. The analysis of the effect of feed rate on surface roughness (Fig. 8) shows that this parameter has a very significant influence, because its increase generates helicoid furrows for the result tool shape and helicoid movement tool-workpiece. These furrows are deeper and broader as the feed rate increases. For this reason, we must employ weak feed rate during turning.

\section{Optimization of cutting conditions}

We consider that the optimal manufacturing conditions for machining hot work steel (AISI4140) are those minimizing the values of cutting force components $(F a$, $F r$ and $F t$ ) and surface roughness $(R a)$ during the hard turning process. The goals and the parameter ranges defined for the optimization process are summarized in Table 8.

Table 9 shows the RSM optimization results (cutting force components $(F a, F r$ and $F t$ ) and surface roughness $(R a)$ in order of decreasing desirability level. The optimized surface roughness $(R a)$ and cutting force components $(F a, F r$ and $F t)$ are $(0.556-0.563) \mu \mathrm{m}$, [(11.655-12.176; (38.620-50.883) and 34.850-38.543)] N, respectively.

\section{Confirmation experiments}

In confirmation of the second-order (quadratic model) response surface model, verification tests were conducted at the optimal conditions (Tests 1 and 2) that were determined by the RMS method and one selected condition (Test 3) that was not carried out in Table 3 . In Test 3, the same depth of cut of $0.3 \mathrm{~mm}$, feed rate of $0.11 \mathrm{~mm} \cdot \mathrm{rev}^{-1}$ and cutting speed $115 \mathrm{~m} . \mathrm{min}^{-1}$ were used. The data from the confirmation runs and their comparisons with the predicted designed cutting forces $(F a, F r$ and $F t)$ and surface roughness $(R a)$ are listed in Table 10. Figure 9 presented the test result, it can be observed that the calculated error is small. The error between experimental and predicted values for $F a, F r, F t$ and $R a$ are lain within 0.008 to $4.130 \%, 0.002$ to $2.838 \%, 0.003 \%$ to 2.856 and -11.698 to $0.179 \%$ respectively. All the experimental values for the confirmation run are within the $95 \%$ prediction interval. Obviously, the second-order response model was very useful for predicting the machining responses.

\section{Conclusion}

This paper presents the findings of an experimental investigation into the effect of cutting speed, feed rate and depth of cut on the cutting force components $(F a$, $F r$ and $F t$ ) and surface roughness $(R a)$ when turning AISI 4041 steel. The ANOVA revealed that depth of cut and feed rate are the most significant factor influencing the response variables investigated. The feed rate and depth of interaction factors provided secondary contribution to the responses investigated. Additionally, the cutting speed also provided secondary contribution to the feed force and thrust force. The comparison of experimental and predicted values of surface roughness and cutting force components shows that good agreement has been achieved between them. Therefore, the developed model can be recommended to be used for predicting surface roughness and cutting force components. The confirmation tests showed that the error between experimental and predicted values of cutting force components $(F a$, $F r$ and $F t$ ) and surface roughness are within 0.008 to $4.130 \%, 0.002$ to $2.838 \%, 0.003 \%$ to 2.856 and -11.698 

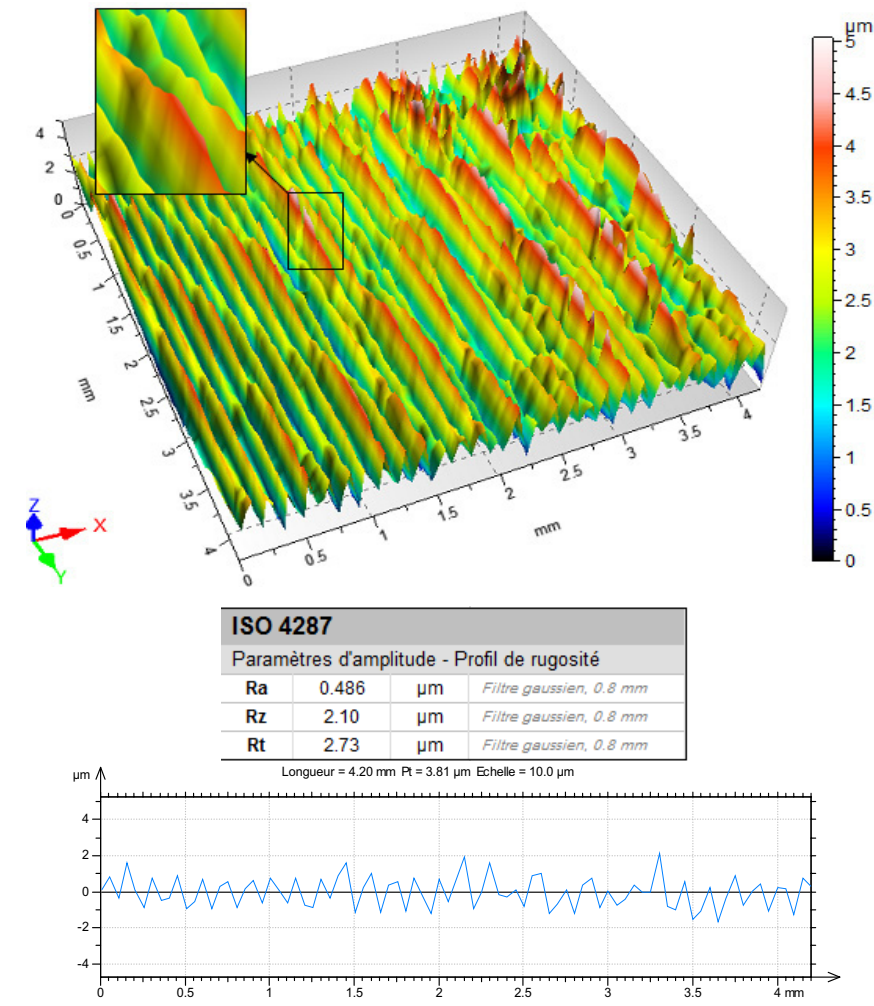

(a)
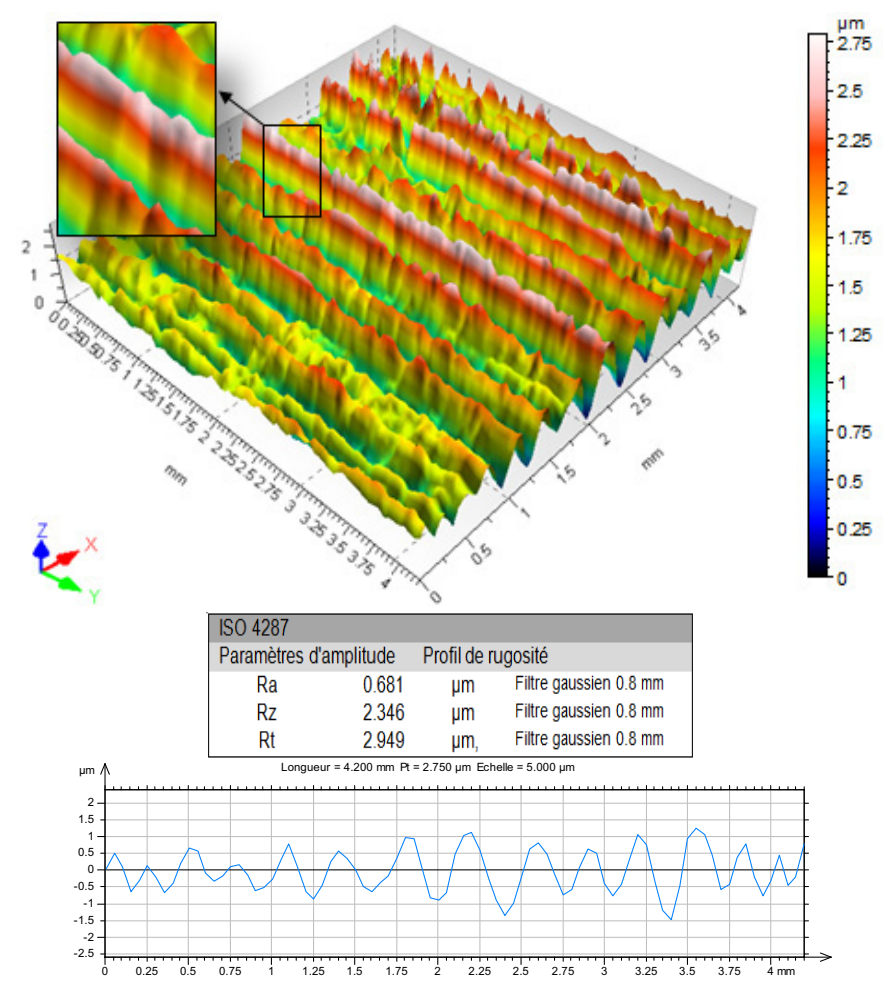

(b)

Fig. 8. 3D-topography plot of the mixed ceramic for; (a) $f=0.08 \mathrm{~mm} \cdot \mathrm{rev}^{-1}$ and (b) $f=0.14 \mathrm{~mm}_{\mathrm{rev}}{ }^{-1}$.

Table 8. Constraints for optimization of cutting conditions.

\begin{tabular}{ccccc}
\hline Condition & Goal & Lower limit & Upper limit & Importance \\
\hline Cutting speed, $V c\left(\mathrm{~m}^{-m_{i}}{ }^{-1}\right)$ & Is in range & 8 & 150 & $* * *$ \\
Feed rate, $f\left(\mathrm{~mm}^{-1} \mathrm{rev}^{-1}\right)$ & Is in range & 0.08 & 0.14 & $* * *$ \\
Depth of cut, $a p(\mathrm{~mm})$ & Is in range & 0.10 & 0.3 & $* * *$ \\
Feed force $F a(\mathrm{~N})$ & Minimize & 12.72 & 108.79 & $* * * * *$ \\
Thrust force $F r(\mathrm{~N})$ & Minimize & 38.62 & 245.97 & $* * * * *$ \\
Tangential force $F t(\mathrm{~N})$ & Minimize & 43.61 & 191.43 & $* * * * *$ \\
Surface roughness $(\mathrm{Ra})$ & Minimize & 0.33 & 1.50 & $* * * * *$ \\
\hline
\end{tabular}

Table 9. Optimization results.

\begin{tabular}{ccccccccc}
\hline Solution No. & $V c\left(\mathrm{~m}_{\mathrm{min}} \mathrm{m}^{-1}\right)$ & $f\left(\mathrm{~mm} \cdot \mathrm{rev}^{-1}\right)$ & $a p(\mathrm{~mm})$ & $F a(\mathrm{~N})$ & $F r(\mathrm{~N})$ & $F t(\mathrm{~N})$ & $R a(\mu \mathrm{m})$ & Desirability \\
\hline 1 & 82.22 & 0.08 & 0.10 & 12.070 & 38.620 & 35.708 & 0.561 & 0.9490 \\
2 & 84.13 & 0.08 & 0.10 & 11.655 & 38.622 & 34.850 & 0.563 & 0.9486 \\
3 & 86.53 & 0.08 & 0.10 & 11.716 & 39.871 & 34.991 & 0.561 & 0.9475 \\
4 & 89.17 & 0.08 & 0.10 & 12.069 & 41.819 & 35.746 & 0.558 & 0.9462 \\
5 & 92.39 & 0.08 & 0.10 & 11.881 & 42.779 & 35.507 & 0.559 & 0.9450 \\
6 & 103.89 & 0.08 & 0.10 & 12.099 & 47.567 & 36.874 & 0.556 & 0.9401 \\
7 & 108.71 & 0.08 & 0.10 & 12.149 & 49.211 & 37.588 & 0.557 & 0.9380 \\
8 & 114.44 & 0.08 & 0.10 & 12.176 & 50.883 & 38.543 & 0.558 & 0.9357 \\
\hline
\end{tabular}


M. Elbah et al.: Mechanics \& Industry 17, 309 (2016)

Table 10. Confirmation experiment.

\begin{tabular}{|c|c|c|c|c|c|c|}
\hline \multirow{2}{*}{ Exp. No. } & \multicolumn{3}{|c|}{ Designing parameters } & \multicolumn{3}{|c|}{ For regression equations } \\
\hline & $V c\left(\mathrm{~m} \cdot \min ^{-1}\right)$ & $f\left(\mathrm{~mm} \cdot \mathrm{rev}^{-1}\right)$ & $a p(\mathrm{~mm})$ & Exp. & Predict. & Error \% \\
\hline \multicolumn{7}{|c|}{ Feed force $(F a)$} \\
\hline 1 & 82.22 & 0.08 & 0.1 & 12.070 & 11.571 & 4.130 \\
\hline 2 & 103.89 & 0.08 & 0.1 & 12.099 & 12.098 & 0.008 \\
\hline 3 & 115 & 0.11 & 0.30 & 86.640 & 81.29 & 0.061 \\
\hline \multicolumn{7}{|c|}{ Thrust force $(F r)$} \\
\hline 1 & 82.22 & 0.08 & 0.1 & 38.620 & 37.524 & 2.838 \\
\hline 2 & 103.89 & 0.08 & 0.1 & 47.567 & 47.566 & 0.002 \\
\hline 3 & 115 & 0.11 & 0.30 & 202270 & 19695 & 2.630 \\
\hline \multicolumn{7}{|c|}{ Tangential force $(F t)$} \\
\hline 1 & 82.22 & 0.08 & 0.1 & 35.708 & 34.688 & 2.856 \\
\hline 2 & 103.89 & 0.08 & 0.1 & 36.874 & 36.873 & 0.003 \\
\hline 3 & 115 & 0.11 & 0.30 & 14604 & 14459 & 0.992 \\
\hline \multicolumn{7}{|c|}{ Surface roughness $(R a)$} \\
\hline 1 & 82.22 & 0.08 & 0.1 & 0.561 & 0.564 & -0.534 \\
\hline 2 & 103.89 & 0.08 & 0.1 & 0.557 & 0.556 & 0.179 \\
\hline 3 & 115 & 0.11 & 0.30 & 0.530 & 0.592 & -11.698 \\
\hline
\end{tabular}

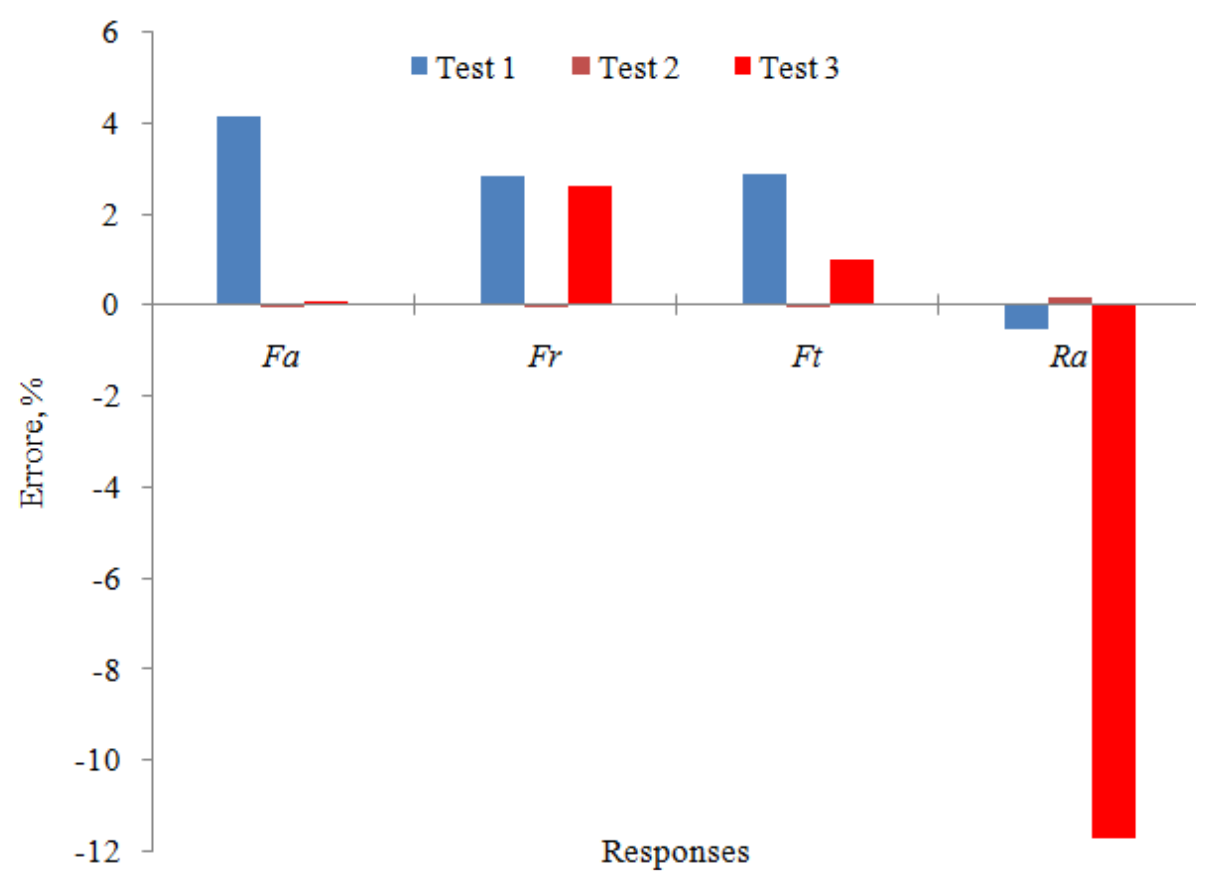

Fig. 9. Verification results for the machining responses comparing response surface model with experiments.

to $0.179 \%$ respectively. The results of ANOVA and the validation experiments confirm that the developed mathematical model shows excellent fit and predicted values are very close to experimental values.

Acknowledgements. The authors would like to thank the Algerian Ministry of Higher Education and Scientific Research (MESRS) and the Delegated Ministry for Scientific Research (MDRS) for granting financial support for CNEPRU Research Project - LMS: No. 0301520090008 (University 08 May 1945 Guelma).

\section{References}

[1] B. Fnides, M.A. Yallese, H. Aouici, Hard turning of hot work steel AISI H11: Evaluation of cutting pressures, resulting force and temperature, Mechanika 4 (2008) 59-63

[2] H. Aouici, M. A Yallese, B Fnides, K. Chaoui, T Mabrouki, Modeling and optimization of hard turning of X38CrMoV5-1 steel with CBN tool, J. Mech. Sci. Technol. 25 (2011) 2843-2851

[3] J.M. Zou, M. Anderson, J.E. Stahl, Identification of cutting errors in precision hard turning process, J. Mater. Process. Technol. 15-154 (2004) 746-750 
[4] J. Rech, A. Moisan, Surface Integrity in finish hard turning of case hardened steels, J. Mach. Tools Manuf. 43 (2003) 54-550

[5] I. Meddour, M.A. Yallese, R. Khattabi, M. Elbah, L. Boulanoua, Investigation and modeling of cutting forces and surface roughness when hard turning of AISI 52100 steel with mixed ceramic tool: cutting conditions optimization, Int. J. Adv. Manufact. Technol. 77 (2014) 13871399

[6] J.S. Dureja, V.K. Gupta, M. Dogra, Design optimization of cutting conditions and analysis of their effect on tool wear and surface roughness during hard turning of AISI-H11 steel with a coated mixed ceramic tool, J. Eng. Manuf. B 223 (2009) 144-1453

[7] P. Thangavel, V. Selladurai, R. Shanmugam, Application of response surface methodology for predicting flank wear in turning operation, Proc. IMechE 220 (2006) 997-1003

[8] H. Öktem, T. Erzurumlu, H. Kurtaran, Application of response surface methodology in the optimization of cutting conditions for surface roughness, J. Mater. Process. Technol. 170 (2005) 11-16

[9] A.A. Premnath, T. Alwarsamy, T. Abhinav, C.A. Krishnakant, Surface roughness prediction by response surface methodology in milling of hybrid aluminium composites, Proc. Eng. 38 (2012) 745-752

[10] A. Ebadnejad, G.R. Karimi, H. Dehghani, Application of response surface methodology for modeling of ball mills in copper sulphide ore grinding, Powder Technol. 245 (2013) 292-296

[11] M. Elbah, M.A. Yallese, H. Aouici, T. Mabrouki, J-F Rigal, Comparative assessment of wiper and conventional ceramic tools on surface roughness in hard turning AISI 4140 steel, Measurement 46 (2013) 304-3056

[12] T. Rajmohan, K. Palanikumar, Application of the central composite design in optimization of machining parameters in drilling hybrid metal matrix composites, Measurement 46 (2013) 1470-148

[13] P.K. Kankar, S.P. Harsha, P. Kumar, Satish C. Sharma, Fault diagnosis of a rotor bearing system using response surface method, Eur. J. Mech. A/Solids 28 (2009) 841857

[14] Z. Hessainia, A. Belbah, M.A. Yallese, T. Mabrouki, J-F. Rigal, On the prediction of surface roughness in the hard turning based on cutting parameters and tool vibrations, Measurement 6 (2013) 1671-168
[15] M.W. Azizi, S. Belhadi, M.A. Yallese, T. Mabrouki, J.-F. Rigal,Surface roughness and cutting forces modeling for optimization of machining condition in finish hard turning of AISI 52100 steel, J. Mech. Sci. Technol. 26 (2012) 410-4114

[16] E.D. Kirby, Z. Zhang, J.C. Chen, Development of an accelerometer based surface roughness prediction system in turning operation using multiple regression techniques, J. Ind. Technol. 4 (2004) 1-8

[17] A. Doniavi, M. Eskanderzade, M. Tahmsebian, Empirical modeling of surface roughness in turning process of 1060 steel using factorial design methodology, J. Appl. Sci. 7 (2007) 2509-2513

[18] J.P. Davim, L. Figueira, Machinability evaluation in hard turning of cold work tool steel (D2) with ceramic tools using statistical techniques, Mater. Des. 28 (2007) 1181191

[19] X. Feng, X. Wang, Development of empirical models for surface roughness prediction in finish turning, J. Adv. Manuf. Technol. 20 (2002) 348-356

[20] I.A. Choudhury, M.A. El-Baradie, Surface roughness prediction in the turning of high-strength steel by factorial design of experiments, J. Mater. Process. Technol. 67 (1997) 55-61

[21] J.D. Thiele, S.N. Melkote, Effect of cutting edge geometry and workpiece hardness on surface generation in the finish hard turning of AISI 52100 steel, J. Mater. Process. Technol. 94 (1999) 216-226

[22] A.I. Khuri, S. Mukhopadhyay, Response surface methodology, WIREs Comput. Stat. 2 (2010) 12-149

[23] D.C. Montgomery, Design and Analysis of Experiments, 6 th edition, John Wiley \& Sons, 2004

[24] R.H. Myers, D.C. Montgomery, in: Response Surface Methodology: Process and Product Optimization Using Designed Experiments, 2nd edition, John Wiley \& Sons, New York, 2002

[25] H. Bouchelaghem, M.A. Yallese, A. Amirat, T. Mabrouki, J-F. Rigal, Experimental investigation and performance analyses of CBN insert in hard turning of cold work tool steel (D3), Mach. Sci. Technol. 14 (2010) 471-501

[26] H. Aouici, M.A. Yallese, K. Chaoui, T. Mabrouki, J.-F. Rigal, Analysis of surface roughness and cutting force components in hard turning with CBN tool: Prediction model and cutting conditions optimization, Measurement 45 (2012) 34-353 